\title{
SWOT ANALYSIS - THE TOOL OF ORGANIZATIONS STABILITY (KFC) AS A CASE STUDY
}

\author{
Soran K. Omer \\ Department of Administration and Accounting, Faculty of Humanities and Social Sciences, \\ Koya University, Koya KOY45, Kurdistan Region - F.R. Iraq. \\ soran.kakarash@koyauniversity.org
}

\section{Original Scientific Paper doi:10.5937/jouproman6-19188}

\begin{abstract}
The study is an effort to test the role of SWOT analysis as a marketing implementation strategy to provide stable condition for organizations. In more detail SWOT analysis is independent variable and organization stability is dependent variable. The methodologies depend on the several problems by reviewing books and journals, as well as tracking down the information the KFC (Kentucky fried chicken) as a global brand and chain food. The result shows that accurate information which is obtained to managers through the analyzing and classifying with the application of SWOT and PEST has the importance role to make strategic plan and stable the organization for a longer time. To conclude, these strategies are playing and leading the essential role the organizations to conduct the best or at least optimal solutions with time and location respectively.
\end{abstract}

Key words: SWOT analysis, Organizations stability

\section{Abbreviations:}

KFC - Kentucky fried chicken.

SWOT - strengths, weaknesses, opportunities and threats.

PEST - Political, Economic, Socio-culture and Technology factors.

4p - Product, price, promotion and placement

\section{Introduction}

To understand and create better condition for stability in an organization, the board of any organization have to understand the matter of fact familiarize their purposes and goals of the organizations and matter of importance know or get their inform of the organizations vision and mission.

One of the crucial steps is reviewing in any organization to obtain optimal performance and organize their aims and goals; they need to check out or review internal and external factors regularly that would directly affect the organizations accomplishment and general improvements. The skillfulness of management is to study these external and internal factors. Also evaluate and properly apply these skills to sketch or distinguish them from organizations or purely makes them stand out.

Organizations that have mission and vision will make effort towards achieving their short term and long term missions and visions. The goals and objectives are need to pursue strongly with high sense of commitment and passion in order to realize stability continuous progressing. It is worthy to annotation that the managing an organization to confirm stability, in the other hands the particular strategic planning process should be employed for this purpose of this exercise SWOT analysis which is part of strategic planning instrument will be considered. 


\subsection{Study problems and questions}

One of the most important threats which is conflicting the managers of organization is when they will make a decision they cannot make a right decision, especially decide through their products price and choosing the place to take the out puts of the companies, at the recent days, there is an effective way or reality tool to sort the strategic plan for the companies which are called (SWOT Analysis), and depend on this position the study problem include some of the questions which are this study attempts to find out suitable and acceptable solution, such as:

Q1) What are the significant of SWOT analysis in companies planning especially Kentucky Fried Chicken (KFC)?

Q2) How can the SWOT analysis stabilize the organization for a longer time globally compare to the others?

Q3) Does organization needs to apply SWOT Analysis for running their business or is there an alternative?

\section{The concepts of SWOT analysis (definitions and visions) by the recent scholars.}

SWOT analysis is a technique which is used to analyze the strengths, weaknesses, opportunities and threats of business (Ommani, 2011) and it is one of the several strategic planning implements that are used by businesses and the other organizations, on the other hands, all factors (Internal and external) are related to the effort, both positive and negative see fig (1) and it's identified and addressed. In order to achieve this task, the process involves four areas of consideration: strengths, weaknesses, opportunities, and threats. It should be noted that, when identifying and classifying relevant factors, the focus is not just on internal matters, but also external components that could influence the success of the project. (Osita et al, 2014).

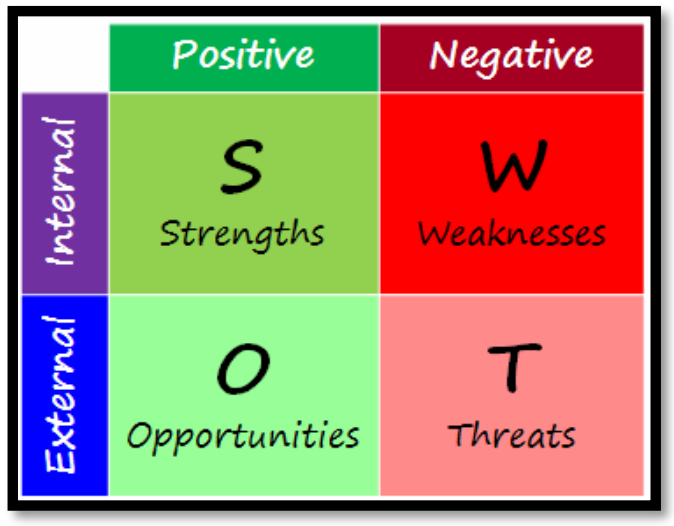

\section{Figure (1) SWOT matrix designed by (Author, 2018)}

In addition, "SWOT is the acronym for a company's strengths, weaknesses, opportunities and threats. According to the advocates of SWOT, strengths refer to inherent abilities to compete and grow strong. Weaknesses are the inherent deficiencies that cripple growth and survival. Strengths and weakness are mostly internal. Opportunities are the good chances and openings available for growth. Threats are externally wielded challenges, which might suppress inherent strengths, accelerate weakness and stifle opportunities from being exploded. To succeed in any field, weaknesses must be overcome through strengths and threats must be transferred into opportunities. The four elements of a SWOT are analyzing undertaking as part of a wider strategic planning." (Kaczmarek, 2016). Also "SWOT refers an acronym of strength, weakness, opportunities and threats. The first two factors (strengths and weaknesses) are related to internal organizational factors, while opportunities and threats cover a wider context or environment in which the entity operates. The first are likely to be under control of the organization but the latter one, although they are no less important when looking at the impact on the enterprise, are not." (Oreski, 2012). 
In addition, (Kaczmarek, 2016) focused on that SWOT elements in more detail are divided into internal and external elements which are clear in other words, the SWOT analysis is based on two pillars: the internal analysis and external analysis of the organization. The strengths and weaknesses belong to the internal field of business, and threats and opportunities belong to the external environment. The tables $(1,2)$ are clearly show explanations below:

Table 1. Internal Factors. (Kaczmarek, 2016)

\begin{tabular}{|c|c|}
\hline Strength and description \\
\hline - & Employees with in high level of Knowledge and capability. \\
- & Good foundation and basic for team work and delegation of responsibilities. \\
- & High engagement external services. \\
- & Strong leadership of top management. \\
- & Attractive maintenance department for new employees. \\
\hline & \\
\hline Weaknesses description \\
- & Number of employees with low willingness for personal development. \\
& Too much focus on "daily activities and problems" and low planned maintenance and \\
- & Dealing with high numbers of priorities. \\
- & High fluctuation of production planning. \\
- & Ineffective and unclear communication. \\
- & Lack of appropriate rewarding system. \\
\end{tabular}

Table 1. External factors. (Kaczmarek, 2016)

\begin{tabular}{|cl|}
\hline Opportunities description \\
\hline - & Continuous personal development. \\
- & Advanced technology. \\
- & Long term relationships with supplier. \\
- & Friendly and safe workplace. \\
- & Standardized equipment. \\
- & Further new diagnostic method development. \\
- & Supporting software tools for activities \\
& \\
\hline Threats description \\
\hline - & Lack of availability operators for clean, inspect, lubricate and tighten, and preventive \\
- & Centraintization of decision making investments and modifications. \\
- & Limited value of stock spare parts. \\
- & No time for preventive maintenance (only weekend). \\
- & Decrease of maintenance budget. \\
- & Lower availability external services. \\
- & Decrease on employee's engagement and motivation. \\
- & Higher dependency on external services. \\
- & Legal constraints. \\
- & Aging machinery and installations. \\
- & Aging employees. \\
\hline
\end{tabular}


But its difference, according to Eggerts viewpoint (2012) with service sector which is focused on that SWOT analysis of bank is here:

\section{1- Strength}

It includes good financial fundamentals, good domestic brand recognition, strong and growing presence, loyal customer, experienced executive management

\section{2- Weaknesses}

Focused on eroding market position, presence performing below expectations, heavy reliance on wholesale funds, high cost brick and mortar infrastructure.

\section{3- Opportunities}

Export of image to other markets, global growing wealth, well positioned to benefit from improving conditions.

\section{4- Threats}

The fourth element is threats which is include increasing global regulation and foreign target markets

\subsection{The Advantage and disadvantages of SWOT analysis}

(Oreski, 2012) emphasizes that the SWOT analysis is simple and useful for organizing information, especially for preliminary research, on the other hand, it also as a basis for more applied and theoretical work. One of the advantages but at the same time disadvantage of SWOT analysis is the fact that it is the method of valuation. The emphasis on the evaluation of the work seems more applied than theoretical. SWOT has proved very useful in understanding the environment of the organization and, consequently, in the strategic planning of their growth and development.and SWOT is use to assess a business or a proposition. This shouldn't be restricted to a business you own, but also to use it for your competitor's business. (Fine, 2009).

On the other hands the "SWOT analysis was used simply because the first contact with the firm made it clear that the sales manager had no idea of how to structure the complex situation. As the authors see it, there were not real alternatives to SWOT. With only one participating person, a rather restricted time frame (for interviews and the number of interviews that could be expected), SWOT seemed as the best option. As mentioned earlier, the application of SWOT was made through several meetings allowing the sales manager to reflect on both the issues and the situation and on the methodological approach for structuring the problem. The time between meetings made up a more productive and interactive analysis. By starting out discussions one day, the sales manager became more attentive to the SWOT factors discussed, and at next meeting he could always add on new relevant issues. However, it was also clear that the analysis could not have been applied without the technological knowledge of the facilitator. Application of SWOT requires a good information and sound knowledge base to succeed. The sales manager did not have sufficient knowledge especially about the external SWOT factors, and the direct engagement of the facilitator as an expert was a requirement for carrying out the analysis. In terms of using SWOT with an illustrative purpose, it is the authors' perception that the manager did get so much insight into SWOT methodologically that he could be able to apply it himself or take on a facilitator role." (Vega, 2004).

"Typically used at the enterprise level, but can be applied at higher levels, for example, in strategic plan in tourism of the destination. Strategic planning for the destination could be a difficult task as there are many possible strategies derived from the assessment of environmental factors. But the decision without a systematic approach would result in less effective strategies." (Oreski, 2012). As well as, SWOT analysis is used commonly in firms and classrooms. 
Normally, it's the centerpiece of situation assessment. (Valentin, 2005).

In addition, Downey \& Technical Information Service (2007) concentrated on when using SWOT analysis, it should be ensured that the internal and external factors are prioritized so that time is spent concentrating on the most significant factors. This should include a risk assessment to ensure that high risk or high impact threats and opportunities are clearly identified and are dealt with in priority order. Also the analysis is pitched at the project or business activity level rather than at a total company level, which may be less actionable. While, the issues identified are retained for later in the strategy formation process.

\subsection{SWOT and PEST analysis and strategy formulation}

(Fine, 2009), emphasis that the questions are crucial even today in business, and should be the starting point when looking at either a new product, or to see how to improve the net profit for a company or organization.

1. What product/s are we selling?

2. What is the process we have in place to sell the product?

3. Who are our customers, who are going to be interested in our product?

4. What ways can we deliver the product to the customers?

5. What are the finances needed to create and sell this product?

6. Who will oversee all the stages from having an idea, to having enough finance to complete the task?

However, a well-established SWOT analysis can benefit a company to understand itself better and it is an important guideline for making a proper marketing strategy plan (Huiru, 2011).
Furthermore, PEST analysis is a scan of the external macro-environment in which an organization exists. It is the one of the beneficial tools for understanding the political, economic, socio-cultural and technological environment that an organization operates in. It can be used for evaluating market growth or decline, and as such the position, potential and direction for a business.

1- Political factors: this factor is consisting of government regulations such as employment laws, environmental regulations and tax policy. Other political factors are trade restrictions and political stability.

2- Economic factors: These affect the cost of capital and purchasing power of an organization

3- Economic factors: this feature is including economic growth, interest rates, inflation and currency exchange rates.

4- Social factors: this factor also has an impact on the consumer's need and the potential market size for an organization's goods and services. Social factors include population growth, age demographics and attitudes towards health.

5- Technological factors: this factor is influence barriers to entry, make or buy decisions and investment in innovation, such as automation, investment incentives and the rate of technological change.

In addition, PEST factors can be classified as opportunities and threats in the SWOT analysis. Figure (3) shows full detail about it. Also, it is often useful to complete a PEST analysis before completing a SWOT analysis. (Downey \& Technical Information Service, 2007). 


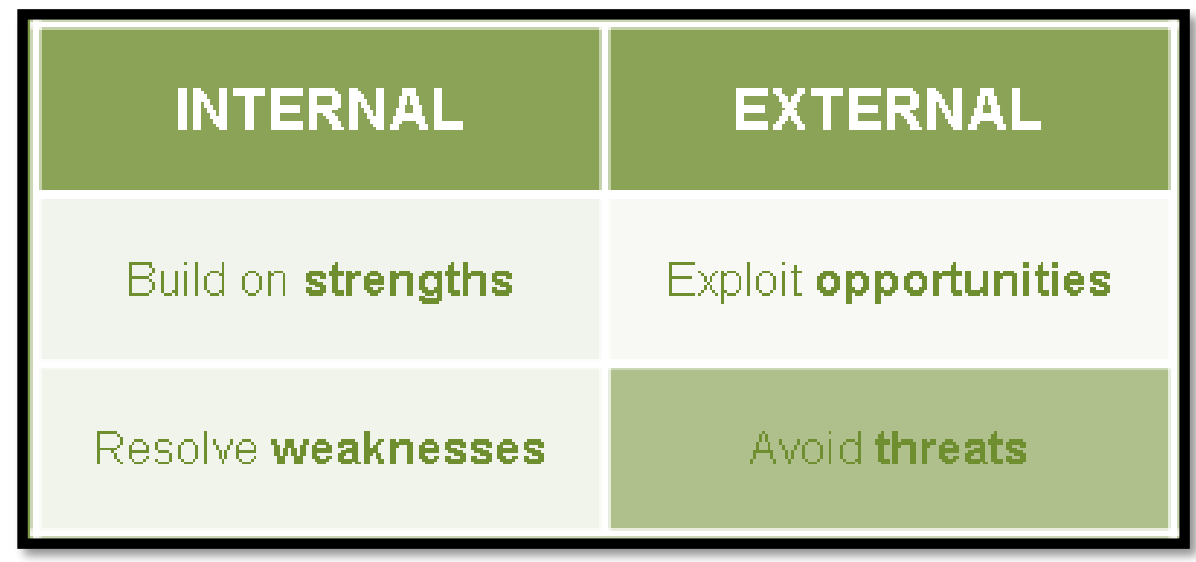

Figure (2) Strategy formulation (Author, 2018)

\section{SWOT Analysis vs PEST Analysis}

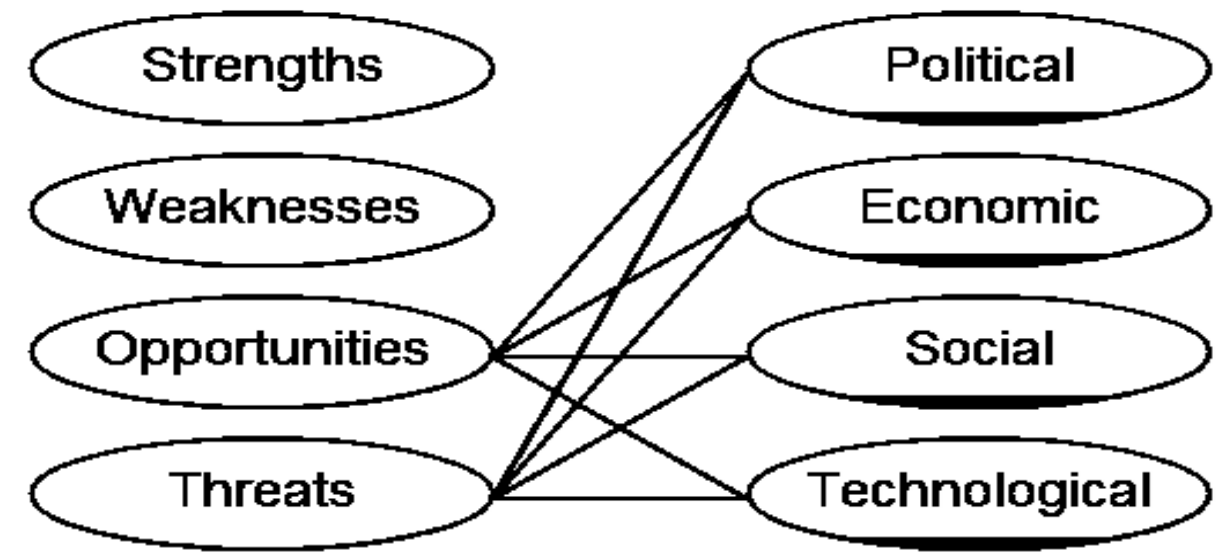

Figure (3) it can be seen SWOT Analysis vs PEST Analysis (Author, 2018)

3. Illustration of KFCs SWOT analysis

To illustrate the theories of this research, formulating marketing strategy with using SWOT analysis, PEST and $4 p$ of KFC.

\subsection{Introduction to the KFC}

Kentucky Fried Chicken which is termed to KFC is a chain of fast food restaurants based in Louisville, Kentucky, in the United States. Plus the KFC products are involves fried chicken, grilled chicken, related southern foods see fig 4 . 


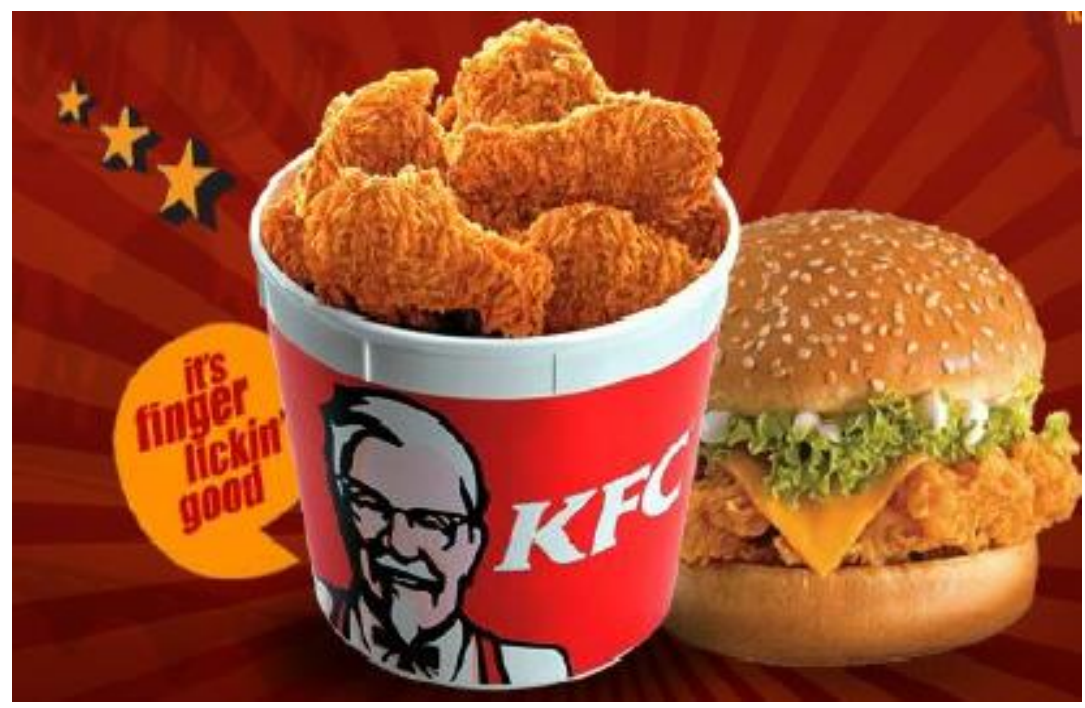

Figure (4) demonstrates KFC's products (web page)

Furthermore, the 4 p's of KFC marketing as a marketing mix are include:

1. Product: KFCs products have the special raspy for chicken products.

2. Pricing: during pricing the KFCs products keep the different points in the mind like they adopt the cost base price strategy. Likewise, pricing of the product contains the government taxes and excise duties and then they come at final stage of control the price of their products. Then, KFC prices of products are a bit high according to the market segment and it is also compatible to the standards of their products. On the other hands the total pounds of chicken served in KFC restaurant annually equal to 1.914 billion, and total KFC chicken pieces sold annually is 5.89 billion and total retail sales is $\$ 8.9$ billion.

3. Promotion : KFC uses the bill boards the major source of advertisement and one of the most important thing that they uses media especially the newspapers to promote their products.

4. Placement: placement of the KFCs product is not important but the placement of the restaurant is key that it can easily judge that the KFC target the place for their restaurant, which is well known and is in the Porsche area where the income level of the people is high then the middle class level.

Table (2) SWOT analysis of KFC

\begin{tabular}{|c|c|}
\hline Strength & Opportunities \\
\hline $\begin{array}{l}\text { 1. Delicious and well liked recipes. } \\
\text { 2. Strongest category among nearest competitors. } \\
\text { 3. Well global penetration. } \\
\text { 4. Well recognized brand logo. } \\
\text { 5. - Strong cash flow via franchisee and license fee. }\end{array}$ & $\begin{array}{l}\text { 1. -Undeveloped markets in many countries. } \\
\text { 2. Increased } 18-25 \text { age groups. } \\
\text { 3. Increasing trends to take meal out of homes. }\end{array}$ \\
\hline Weaknesses & Threats \\
\hline $\begin{array}{l}\text { 1. Most KFC items have close substitutes in market. } \\
\text { 2. No product innovations. } \\
\text { 3. Lack of control in joint venture arrangements. } \\
\text { 4. - Inconsistent quality of service in many outlets. }\end{array}$ & $\begin{array}{l}\text { 1. Other cheap alternatives available. } \\
\text { 2. Bird flu. } \\
\text { 3. Cannibalization of own products. } \\
\text { 4. Changing health trends of customers. } \\
\text { 5. - High calorie food. }\end{array}$ \\
\hline
\end{tabular}




\section{Conclusions}

This case project has conducted and pointed the role of SWOT analysis, in terms of gathering and collecting information in to the interior and external environments of the organization with annual data base, while SWOT is simplifying the actions however, managers need to skill limitation for the factors that can effect on the organizations products and services after this strategy SWOT analysis depend on PEST analysis to limit the strength, opportunities, weaknesses and threats, and all of these elements have expressed the other things or indirectly related such as financial, staffs, knowledge and make new product or the same product of the competitive organization. Moreover, according to KFC's statistics as they claim that KFC stabilities related with their marketing strategies and there are a good SWOT analysis and accurate PEST to the segment the market especially they can succeed to choose the product, logical pricing, attractive promotion and factual market or placement.

\section{References}

1. Downey, J. and Technical Information Service (2007) Strategic analysis tools; Topic Gateway Series No. 34, The Chartered Institute of Management Accountants (CIMA).

2. Eggert, C. (2012) A strategy analysis of the "Big Five" Canadian banks.

3. Fine, L. G. (2009) the SWOT analysis; using your strength to overcome weaknesses, using opportunities to overcome threats, Kick It, LLC.

4. Hurino, D. (2011) the importance of strategy management, Savonia university of applied science.

5. Kaczmarek, M. J. (2016) SWOT analysis for planned maintenance strategy - a case study, International Federation of Automatic Control 49-12,Pp. 674-679, Hosting by Elsevier Ltd.

6. Ommani, A. R. (2011) for strength, weaknesses, opportunities and threats
SWOT analysis for farming system businesses management, case of wheat of shadervan district, Shoushtar Township, Iran. African Journal of Business Management Vol. 5(22), pp. 9448-9454, Available online at http://www.academicjournals.org/AJBM ISSN 1993-8233

7. Oreski, D. (2012) Strategy development by using SWOT- AHP, TEM Journal, Vol. 1, No. 4.

8. Osita, I. C., Oneybuchi, I. R., Justina, N. (2014) Organizations stability and productivity; the role of SWOT analysis an acronym for strength, weaknesses, opportunities and threat, International Journal of Innovative and Applied Research, Volume 2, Issue 9,Pp. 23-32.

9. Tiwebyse, A. Y. (2015) A business plan development: the case of paint company Douala- Cameroon, Uiversity of the Basque Country. Donpstia - San Sebastan.

10. Valantin, E. K. (2005) A way with SWOT analysis: use defensive/ offensive evaluation instead, The Journal of Applied Business Research - Volume 21, Number 2 , Weber State University.

11. Vega, P. E. J. (2004) Strategic analysis and recommendation for XYZ research corporation, master thesis, University of Florida.

Website:

www.KFC.com 